\title{
Frost flowers in the laboratory: Growth, characteristics, aerosol, and the underlying sea ice
}

\author{
H. K. Roscoe, ${ }^{1}$ B. Brooks, ${ }^{2}$ A. V. Jackson, ${ }^{2}$ M. H. Smith, ${ }^{2}$ S. J. Walker, ${ }^{2}$ R. W. Obbard,,${ }^{1,3}$ \\ and E. W. Wolff ${ }^{1}$ \\ Received 4 October 2010; revised 18 March 2011; accepted 25 March 2011; published 17 June 2011.
}

[1] In the laboratory, we have investigated the growth and composition of frost flowers. Their ionic composition has shown little difference from those of field measurements. Young frost flowers grown on sea ice are saline, leading us to speculate that wicking occurs continually during their growth on sea ice. The surface area of frost flowers is only a little larger than the area of ice underneath, consistent with recent field measurements from the Arctic. Time-lapse photography has allowed us to observe the extreme mobility of freshly forming sea ice, at the stage at which the mush has become rather solid, and continuing while the flowers grow. This mobility results in new brine being expelled to the surface, which therefore remains wet. During various stages of frost flower growth, we observed their freshly formed dendritic parts rapidly diminishing in size after contacting the surface, consistent with repeated wicking. Frost flowers proved to be very stable in the presence of wind, such that no aerosol was observed when wind was blown across them in the laboratory chamber. This is consistent with recent field observations of frost flowers coexisting with wind-blown snow.

Citation: Roscoe, H. K., B. Brooks, A. V. Jackson, M. H. Smith, S. J. Walker, R. W. Obbard, and E. W. Wolff (2011), Frost flowers in the laboratory: Growth, characteristics, aerosol, and the underlying sea ice, J. Geophys. Res., 116, D12301, doi:10.1029/2010JD015144.

\section{Introduction}

[2] Frost flowers growing on sea ice have been implicated in two important polar processes: loss of tropospheric ozone in polar spring (often called ozone depletion events, ODEs), and the apparent negative non-sea-salt sulfate found in some ice cores.

[3] Loss of tropospheric ozone in polar spring is now well documented [e.g., Bottenheim et al., 2002], and the importance of $\mathrm{BrO}$ in this removal is firmly established [Platt and Lehrer, 1997]. The process occurs in both the Arctic and Antarctic [e.g., Friess et al., 2004]. Formation of large amounts of $\mathrm{BrO}$ takes place via the so-called bromine explosion, which creates gas-phase $\mathrm{Br}$ atoms from liquidphase $\mathrm{Br}^{-}$ions via heterogeneous reactions involving $\mathrm{HOBr}$ and sunlight. During formation of new sea ice, the increased salinity of the brine skim causes increased $\mathrm{Br}^{-}$concentrations, and zones of new ice formation are implicated in $\mathrm{BrO}$ production [Kaleschke et al., 2004].

[4] Ice cores contribute a powerful record of past climate changes provided they can be interpreted accurately. The interpretation of sea salt in ice cores depends on understanding the extent to which it derives from open water, or

\footnotetext{
${ }^{1}$ British Antarctic Survey, Cambridge, UK.

${ }^{2}$ School of Earth and Environment, University of Leeds, UK.

${ }^{3}$ Now at Thayer School of Engineering, Dartmouth College, New Hampshire, USA.

Copyright 2011 by the American Geophysical Union. 0148-0227/11/2010JD015144
}

from sea ice sources, including frost flowers. One diagnostic of the sea ice source also affects the interpretation of sulfate in Antarctic ice cores: sea salt in coastal Antarctic aerosol, snowfall [Wagenbach et al., 1998], and ice cores [Rankin et al., 2002] is depleted in sulfate relative to other seawater ions. The reason for the depletion is that, at temperatures below seawater's initial freezing point of $-2^{\circ} \mathrm{C}$, ice freezes from the remaining brine, then below $-8^{\circ} \mathrm{C}$ mirabilite $\left(\mathrm{Na}_{2} \mathrm{SO}_{4} \cdot 10 \mathrm{H}_{2} \mathrm{O}\right)$ is precipitated into the solid ice, so that the remaining brine is relatively depleted in sulfate. This suggests that areas of sea ice formation at the low temperatures of winter and spring are the source of the sea salt aerosol in ice cores. The fractionation has to be allowed for in the calculation of the non-sea-salt portion of sulfate in aerosol and ice [Rankin et al., 2002].

[5] Frost flowers are hoar frost-like structures that grow on freshly freezing ice at low temperatures (Figure 1). On sea ice, their fine structure provides a means of wicking surface brine toward the colder lower atmosphere. Relative to seawater, the surface brine will be enhanced in $\mathrm{Br}^{-}$and most other ions, and depleted in sulfate, and in principle they should therefore be important both to tropospheric ODEs and to sulfate depletion in ice cores. Frost flowers themselves could facilitate the bromine explosion by providing a larger salt-rich surface area, as could aerosol derived from frost flower disintegration in stronger winds.

[6] Analysis of Antarctic frost flowers shows that they are highly saline and that sulfate is strongly depleted relative to sodium [Rankin et al., 2002; Alvarez-Aviles et al., 2008]. The unusual ionic ratios are common to frost flowers and coastal 


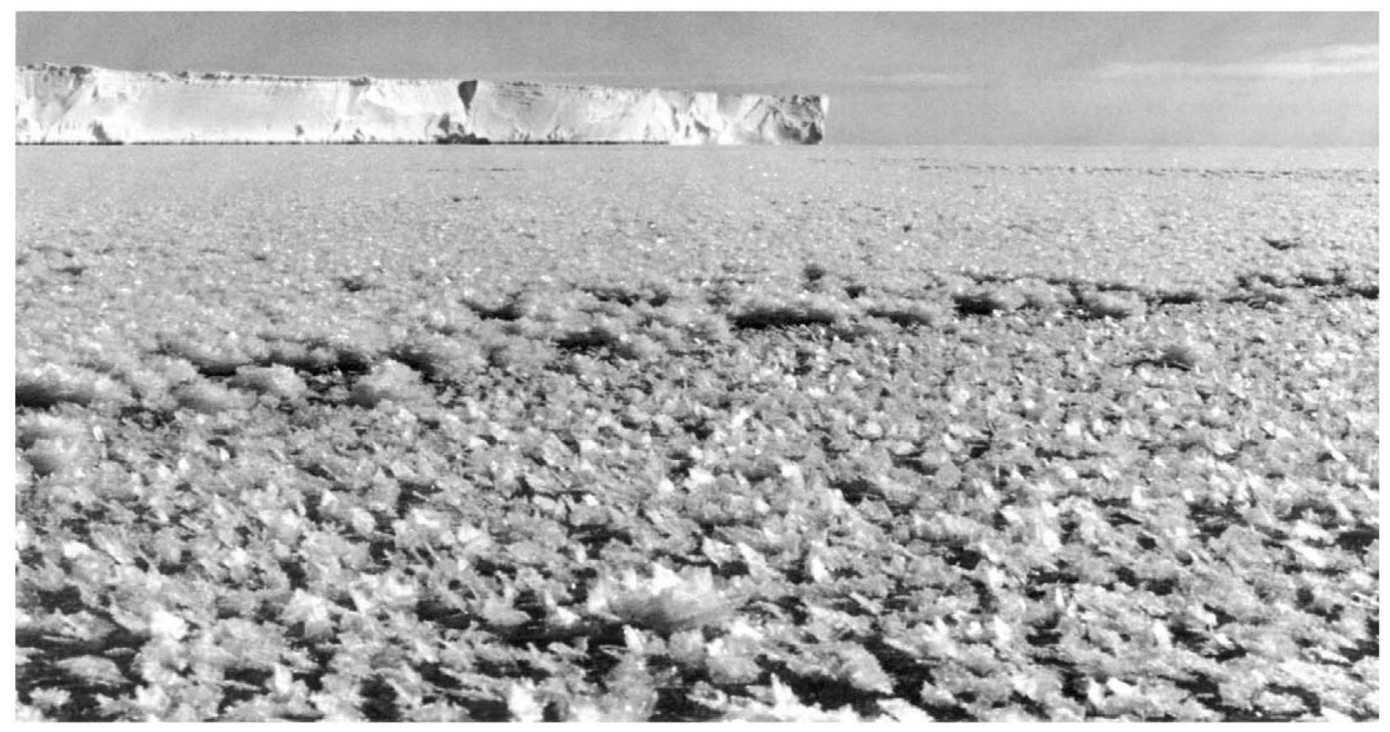

Figure 1. Frost flowers growing on the surface of newly formed ice near Halley in Antarctica (courtesy R. Ladkin, BAS). Flowers are several centimeters tall and often extend large distances from the coast as here.

aerosol and snow, suggesting that the sea ice surface is indeed the likely source of the aerosol seen in coastal Antarctica, although it does not necessarily mean that frost flowers themselves are the source. The maximum concentration of sea salt aerosol in the atmosphere occurs during winter and spring, when the distance to open water is greatest [Hall and Wolff, 1998], so that a more local sea ice source such as frost flowers or the brine that occurs at the same time as their formation would explain the seasonality as well as the composition of sea salt aerosol at Antarctic sites.

[7] However, it is not obvious how the salt from such sea ice surfaces is mobilized into the atmosphere. Although it seems reasonable that frost flowers should be more fragile and so more easily dispersed than flat brine skims, such dispersal has not been observed. Furthermore, Simpson et al. [2007] identified enhanced bromine compounds in air that had not been at frost flower sites. More recently, Yang et al. [2008] have proposed that wind-blown snow in the sea ice zone can be dehydrated to the extent that the saline nuclei provides the sea salt aerosol, but although saline snow is observed above sea ice [Massom et al., 2001], the exact source of the salinity is unclear and the extent to which saline snow can be dispersed by wind is even less clear. Recent observations by Obbard et al. [2009] suggest that frost flowers may be one source of salinity in snow that can be remobilized by wind.

[8] In the past, frost flowers were investigated in the field by Perovich and Richter-Menge [1994] and in the laboratory by Martin et al. [1996], who demonstrated their formation on brine-rich slush expelled from ice formation just below the surface, at temperatures down to $-35^{\circ} \mathrm{C}$. In this paper, we observed frost flower growth in the laboratory at air temperatures below $-45^{\circ} \mathrm{C}$, by including measurements at temperatures significantly colder than those of previous work, we expected much faster rates of growth. We also measured their chemical composition and their surface area; composition and surface area are critical properties of frost flowers in determining the rate of diffusion of reactive bromine species to the atmosphere. Finally, we investigated whether aerosol can result from frost flowers.

\section{Frost Flower Apparatus}

[9] Frost flowers were grown in a purpose-built tank large enough to simulate some aspects of open water processes, housed in a cold room. The cold room, built by Design Environmental, was a stainless steel lined chamber of internal dimensions $3 \mathrm{~m}$ by $2 \mathrm{~m}$ and $2.2 \mathrm{~m}$ high, whose temperature could be controlled down to $-60^{\circ} \mathrm{C}$. It had ports to a larger outer room for additional equipment and through which samples could be drawn for analysis by aerosol equipment outside the chamber. It had double wide entry doors with air lock, to permit access to the chamber without unduly disturbing the internal conditions. A programmable control unit enabled operation of the chamber to be automated, so that complex sequences could be executed without manual intervention. Cooling and heating rates were typically $1^{\circ} \mathrm{C} / \mathrm{min}$, though response was somewhat slower as the minimum operating temperature was reached. If programmed to cool to $-60^{\circ} \mathrm{C}$, it reached $-25^{\circ} \mathrm{C}$ within $40 \mathrm{~min}$ and $-55^{\circ} \mathrm{C}$ within two hours. The chamber had a closed circuit air circulation system, with particle-free (zero) air being circulated past the cooling coils. The temperature and humidity in the chamber was logged against time to a computer linked to the chamber controller.

[10] The seawater tank was similar to that used by Martin et al. [1996], except that the whole system was fully enclosed in perspex for better control of air cleanliness, temperature and humidity (Figure 2). Air was recirculated by a powerful fan, via filters and a honeycomb flow straightener, though the filter was later removed and extra air pumping was added to increase wind speed (see below). The air inside the tank system could therefore be kept cleaner than the general air inside the cold room.

[11] The tank had a separate heating system for the tank water, to increase control and flexibility. In order to measure 


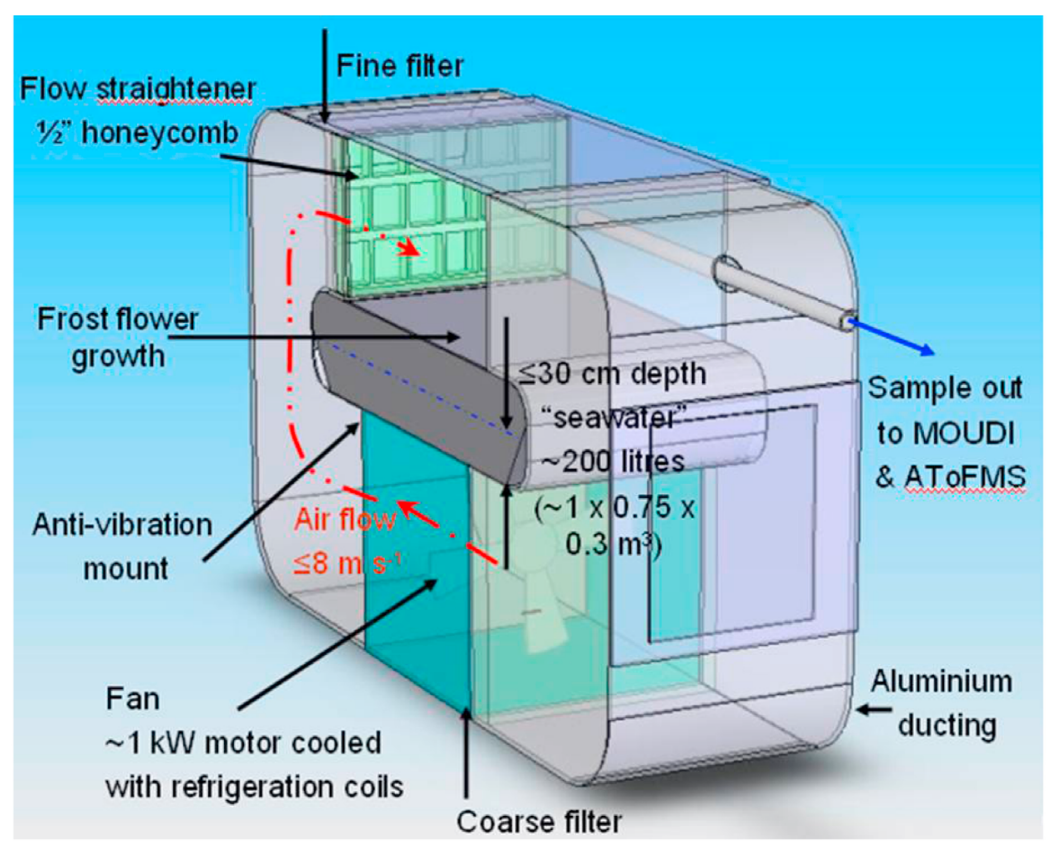

Figure 2. Sketch of the seawater tank and housing in the cold room at Leeds. The tank was $1.5 \mathrm{~m} \times 0.8 \mathrm{~m}$, with $0.2 \mathrm{~m}$ of water depth and $25 \mathrm{~cm}$ of head space. The tank was made of stainless steel and the housing was made of Plexiglass. Fans and filters for recirculating air were mounted at one end, with flexible ducting.

the way in which temperature evolved through the sea ice and overlying air during ice growth, the tank incorporated an array of 35 thermistors. These were betatherm epoxyencapsulated thermistors, biased such that their maximum sensitivity was at $-35^{\circ} \mathrm{C}$. The lowest 32 thermistors were at $2 \mathrm{~mm}$ spacing from $2 \mathrm{~mm}$ above the bottom of the tank, with the upper 3 thermistors being at $10 \mathrm{~cm}$ spacing. The fine spacing was particularly important in the surface few $\mathrm{mm}$ of slush, where the liquid brine could become concentrated enough to be colder than $-3^{\circ} \mathrm{C}$.

[12] The tank was heated via a feedback loop controlled via Matlab to maintain the water beneath the ice above its freezing point. A pair of aquarium pumps were mounted in the base of the water tank to circulate the water and ensure it did not stratify. There was no humidity control below $5^{\circ} \mathrm{C}$, below this any excess vapor deposited as ice on the chamber cooling coils. Humidity was monitored at $5 \mathrm{~cm}$ above the ice surface using a Michell chilled mirror frost point hygrometer.

[13] The tank was filled with $200 \mathrm{~L}$ of seawater made from synthetic sea salt (Hobby Marin salt, Dohse Aquaristik $\mathrm{KG}$, Germany), being mixed to a variety of salinities up to $40 \%$ by weight. Standard seawater has salinity 35 Practical Salinity Units (PSU), the PSU being very similar to parts per thousand. At seawater salinities greater than about 20 PSU there is no density maximum above the freezing point. This means that standard seawater could cool throughout the tank and start to freeze within the liquid, unlike fresher water that cools at the surface and so freezes only at the surface. Because the eventual ice floats, a mush forms at and just below the surface rather than throughout the depth of liquid. The mush then expels brine in all directions as more freezing occurs. As further cooling occurs, brine channels in the top layer of mush become brine pockets: brine can no longer move rapidly within that part of the ice. As more water under the ice freezes, pressure would build up under the ice if the seawater tank were rigid.

[14] Earlier laboratory measurements by others appeared to show brine pools on the surface during freezing. We believe they may have suffered from flooding by underlying brine because of the lack of pressure relief in their rigid tank. We installed two crude but effective methods of pressure relief: (1) partially inflated bicycle inner tubes in the base of the water tank, weighted down so that they did not contact the surface and (2) black polythene envelopes at the upper part of the tank sides, containing pillows of bubble wrap, and also containing metal strips that could be clamped to the tank sides to keep most of the envelopes below the water surface. As a result of these precautions, there was no evidence of cracks or flooding during the freezing process. The second pressure relief method above minimized any residual pressure, though a very small residual pressure is always possible without the kind of balloon and siphon system used by Style and Worster [2009].

[15] A cooling cycle would start by equilibrating the cold room and water tank system at $20^{\circ} \mathrm{C}$ and $60 \%$ relative humidity until the tank system and the room air were at the same temperature (up to $12 \mathrm{~h}$ ), then cooling as quickly as possible. Because the tank system is partly isolated from the main chamber, the tank is warmer than the main chamber for some time. Water vapor in the cold room would deposit on its cooling coils, but water vapor in the tank system would deposit on its coldest surface, usually the inside of the system roof. Inside the tank system a humidity gradient results, and evaporation and transport of water vapor from the water/ice surface occurs. Due to the low holding capacity of air at the cooler temperatures, the air above the water/ice surface was usually supersaturated.

[16] The powerful centrifugal fan inside the water tank system could blow wind over the ice surface, and was intended 


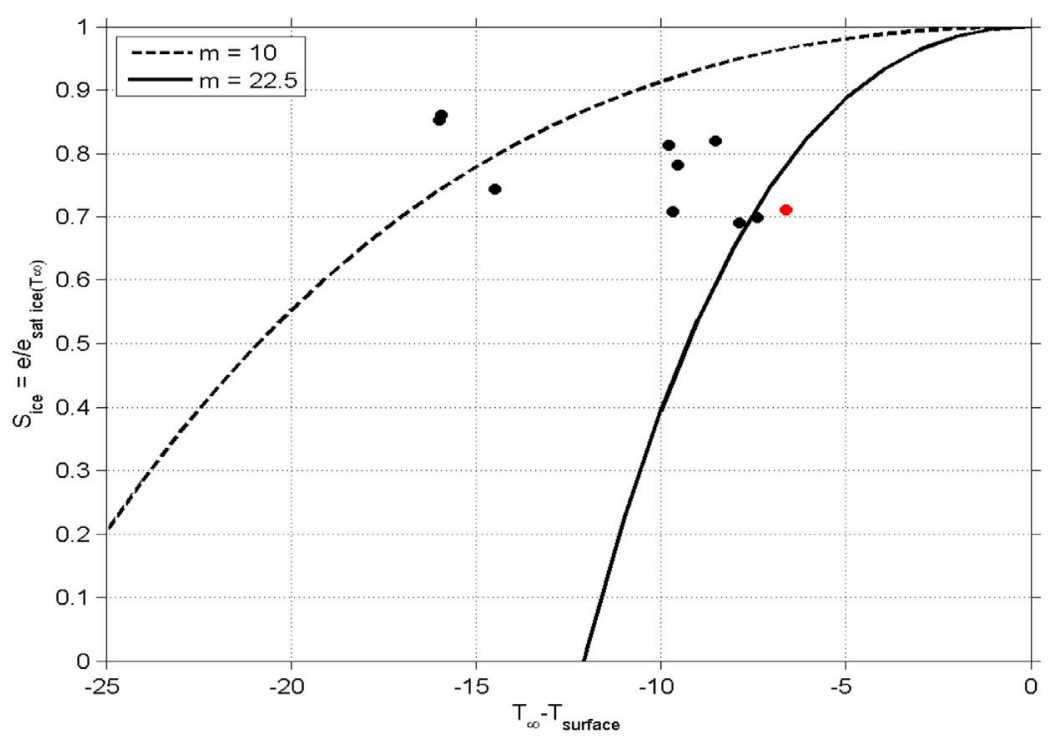

Figure 3. Relative humidity with respect to ice $\left(\mathrm{S}_{\mathrm{i}}\right)$ as a function of the temperature difference $\left(\mathrm{T}_{\infty}-\mathrm{T}_{\mathrm{i}}\right)$ between the air and the surface of the seawater ice, showing regions where frost flowers form (in black) and are not observed (in red). Following Style and Worster [2009], solid and dashed curves are given by equation (1) with $\mathrm{ML} / \mathrm{RT}_{\infty}=22.5$ and 10 , respectively.

to break up and disperse frost flowers. However, the resistance of the system was greater than anticipated and maximum useful winds were only $4 \mathrm{~m} / \mathrm{s}$. Hence a large bellows system was built to sit inside the cold room alongside the tank system, capable of generating bursts of wind up to $12 \mathrm{~m} / \mathrm{s}$ for a few seconds. It consisted of a cylinder of diameter $0.6 \mathrm{~m}$ and length $1.5 \mathrm{~m}$, inside which a piston a few $\mathrm{mm}$ smaller in diameter could be pushed to generate a large flow through a $100 \mathrm{~mm}$ diameter tube leading back to the tank.

[17] The freezing of the ice and the growth of frost flowers was observed by a camera (Canon D60), with full image size at the ice of about $140 \times 240 \mathrm{~mm}$. The normal frame rate was once per minute, and frames could be put together to make movies. The ice image was illuminated by strips of white light-emitting diodes. The LEDs were housed in translucent plastic tubing that acted as protection against water and as an optical diffuser. LEDs were used rather than conventional bulbs as the heat from them was negligible, and so did not affect the air temperature just above the ice.

[18] Frost flowers were sampled by cutting through their midpoint or base with a spatula, which was usually large enough that the flower was left on the spatula. This was then tipped directly into a small handheld container. Brine from the surface was sampled by scooping with the curved end of a spatula, and pouring it directly into a small handheld container. The surface had a solid skim at the time of becoming cloudy (see the auxiliary material), well in advance of flowers starting to grow and well before taking any of our brine samples, so very little if any ice was included in the brine.

\section{Frost Flower Growth, Composition, Surface Area, and Wicking}

[19] Style and Worster [2009] discussed a variety of possible regimes during the freezing of water, only one of which (an unsaturated far field, and evaporation supersaturated at the surface) was feasible for frost flower growth in the field. Style and Worster [2009] used fresh water, so before embarking on more comprehensive measurements with seawater ice, we performed their experiment but with seawater. Figure 3 shows that we did indeed operate at the regime of an evaporation-supersaturated surface (close to the dashed line in Figure 3).

[20] In more detail, Figure 3 illustrates the relative humidity with respect to ice $\left(\mathrm{S}_{\mathrm{i}}\right)$ as a function of the temperature difference $\left(T_{\infty}-T_{i}\right)$ between the atmosphere and surface of fresh water ice. The regions where frost flowers were observed (shown in black) and were not observed (shown in red) are denoted with error bars indicating one standard deviation. The solid line indicates

$$
\mathrm{S}_{\mathrm{i}}>(1+\mathrm{m} \tau) \mathrm{e}^{-\mathrm{m} \tau},
$$

where $\mathrm{m}=\mathrm{ML} / \mathrm{RT}_{\infty}$ and $\tau=\left(\mathrm{T}_{\infty}-\mathrm{T}_{\mathrm{i}}\right) / \mathrm{T}_{\infty}$, where $\mathrm{M}$ is the molar mass of water, $\mathrm{L}$ is the latent heat of vaporization per unit mass, and $\mathrm{R}$ is the gas constant.

[21] The expected value of $\mathrm{ML} / \mathrm{RT}_{\infty}$ at $\mathrm{T}_{\infty}=272 \mathrm{~K}$ is 22.5 . Style and Worster [2009] found that frost flowers could theoretically form above this line, but in practice greater supersaturation was required, so that they found frost flowers only above $\mathrm{m}=10$ (dashed line). In our experiments frost flowers formed in this regime with values of $m$ closer to the theoretical one of 22.5. Figure 3 substantially reproduces the result of Style and Worster [2009] and shows that we are working in the correct regime (the one expected in the field), so we could proceed with confidence.

[22] Salinity of melted samples that were not tested for ionic composition was measured by an optical refractometer (Omega, UK). The refractometer was able to measure salinity to \pm 1 PSU and was calibrated before each experiment using 
Table 1. Measurements of Frost Flower and Other Relevant Salinities

\begin{tabular}{|c|c|c|}
\hline Conditions & Salinity (PSU) & References \\
\hline Standard mean ocean water & 35 & Dauphinee et al. [1980] \\
\hline FF, Arctic & $50 \pm 5$ & Ulander et al. [1995] \\
\hline $\begin{array}{l}\mathrm{FF},-15 \text { to }-25^{\circ} \mathrm{C} \\
\text { Arctic }\end{array}$ & $\sim 100$ & $\begin{array}{l}\text { Perovich and } \\
\quad \text { Richter-Menge [1994] }\end{array}$ \\
\hline $\mathrm{FF}$, lab, -20 to $-30^{\circ} \mathrm{C}$ & $50-110$ & Martin et al. [1996] \\
\hline FF, Halley, $-20^{\circ} \mathrm{C}$ & $\sim 13$ & Rankin et al. [2000] \\
\hline FF, Halley, $-20^{\circ} \mathrm{C}$ & $10-110$ & Rankin et al. [2002] \\
\hline Brine & $35-85$ & Rankin et al. [2002] \\
\hline Sea ice & $10-20$ & Rankin et al. [2002] \\
\hline $\mathrm{FF}$, lab, -30 to $-20^{\circ} \mathrm{C}$ & $\begin{array}{c}0-142 \\
(\text { mean } 95 \pm 42)\end{array}$ & This work \\
\hline Brine, lab, -30 to $-20^{\circ} \mathrm{C}$ & $\begin{array}{c}18-120 \\
(\text { mean } 64 \pm 25)\end{array}$ & This work \\
\hline
\end{tabular}

a commercially available Atlantic seawater standard (Ocean Scientific International Ltd, UK) of salinity 35.0 \pm 0.07 PSU [Dauphinee et al., 1980].

[23] The salinity of melted frost flowers and brine was up to a factor of 3 to 4 larger than that of the salt water used to grow them (see Table 1), in support of previous observations in the Arctic and Antarctic [Perovich and Richter-Menge, 1994; Rankin et al., 2000, 2002] and in the laboratory [Martin et al., 1996]. A general increase in frost flower and brine salinity was found as the temperature decreased (Figure 4), as expected from increased salt exclusion from the thickening ice, and again in agreement with observations in the Arctic [Perovich and Richter-Menge, 1994; Alvarez-Aviles et al., 2008] and in the laboratory [Martin et al., 1996]. Figure 4 also shows that frost flowers were more saline than their accompanying brine by a factor of 1.2 to 1.6 , more so at lower temperatures: once again consistent with previous observations in the Antarctic [Rankin et al., 2002] and in the laboratory [Martin et al., 1996].

[24] Figure 5 shows that the salinity of frost flowers and brine was linearly dependent on the initial tank water salinity, before starting the freezing process, with a slightly stronger correlation for brine $(\mathrm{R}=0.989)$ than for frost flowers $(\mathrm{R}=$
$0.975)$. Both correlations were statistically significant above the $97 \%$ level. This result is somewhat surprising. The salinity of brine in the system that is in contact with ice is controlled only by the local temperature and the equilibrium freezing point line, provided equilibrium has been established, the time for which should be a few minutes for brine $1 \mathrm{~mm}$ thick. For the frost flowers the net measured salinity is a function of this local temperature (which should be independent of the initial tank salinity) and the proportion of fresh ice to brine in the flower. If freezing was fast, then the fresh ice may itself contain nonequilibrium higher concentrations of salt, but this is a second order effect on the net concentration of the brine/ice mixture. It must therefore be the case that for a tank of higher salinity water, more wicking is occurring, perhaps suggesting that at higher salinities the brine layer from which wicking occurs is thicker and more mobile. For the slush, this result is more likely a methodological one: the liquid brine salinity should be independent of the initial salinity, but it is likely we sample a brine/ice mixture that again will contain more brine if the initial salinity was higher, because of the inherent difficulty of sampling small flowers and thin layers of brine.

[25] The ionic composition of some melted frost flower samples, after dilution by 1000 with high purity water, was measured at BAS. We used a Dionex DX500 ion chromatograph with a $4 \mu \mathrm{m}$ AS18 separator column for anions and a $3 \mathrm{~mm}$ CS12A $5 \mu \mathrm{m}$ separator column for cations. Simultaneous injection of the samples was performed using an AS autosampler which is equipped with a $500 \mathrm{ml}$ loop for the anions and a $250 \mathrm{ml}$ loop for the cations. We used isocratic elution with $22 \mathrm{mM}$ potassium hydroxide for the anions and $20 \mathrm{mM}$ methane sulfonic acid for the cations, each taking $16 \mathrm{~min}$. Flow rates were 1.0 and $0.5 \mathrm{ml} / \mathrm{min}$ for the anions and cations, respectively, and the accuracy was $\pm 5 \%$ for the major ions.

[26] For technical reasons, concentrations of $\mathrm{Br}^{-}$were never reliably measured. Total salinity of the melted frost flower samples was measured at BAS by a Hach sensION5 ISFET conductivity meter with internal temperature correction (accuracy $\pm 0.1 \mathrm{PSU}$ ).

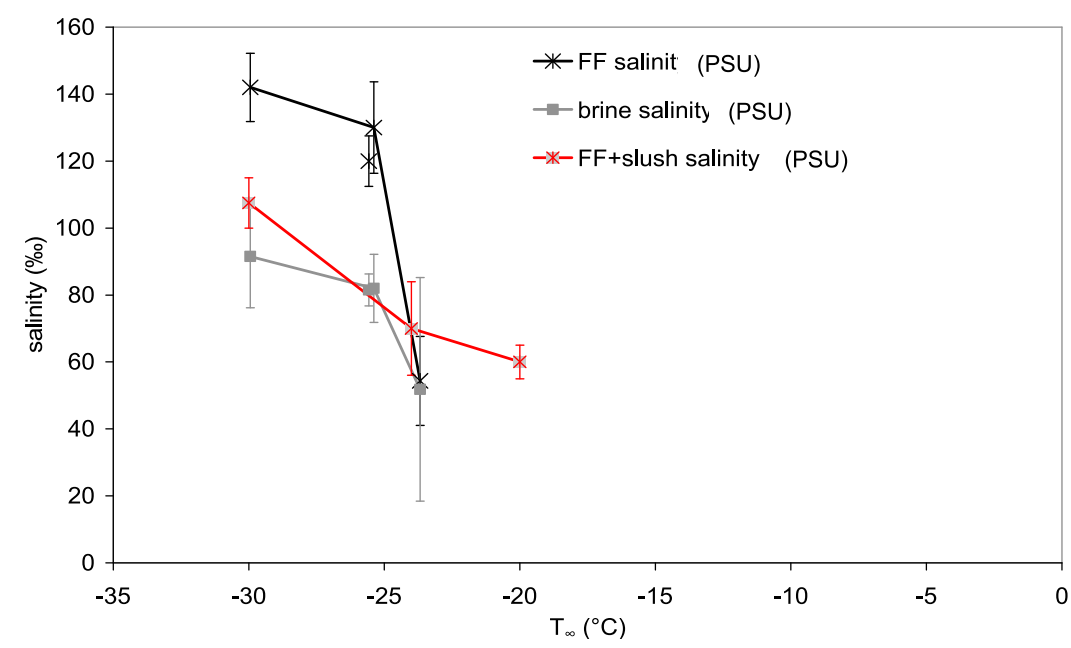

Figure 4. Salinity of artificial frost flowers (black crosses) and brine (gray squares) sampled from frozen synthetic seawater at distant ambient air temperatures of -30 to $-20^{\circ} \mathrm{C}$ and the comparison with previous measurements by Martin et al. [1996] (in red). Error bars show 1 standard deviation of repeat measurements. 


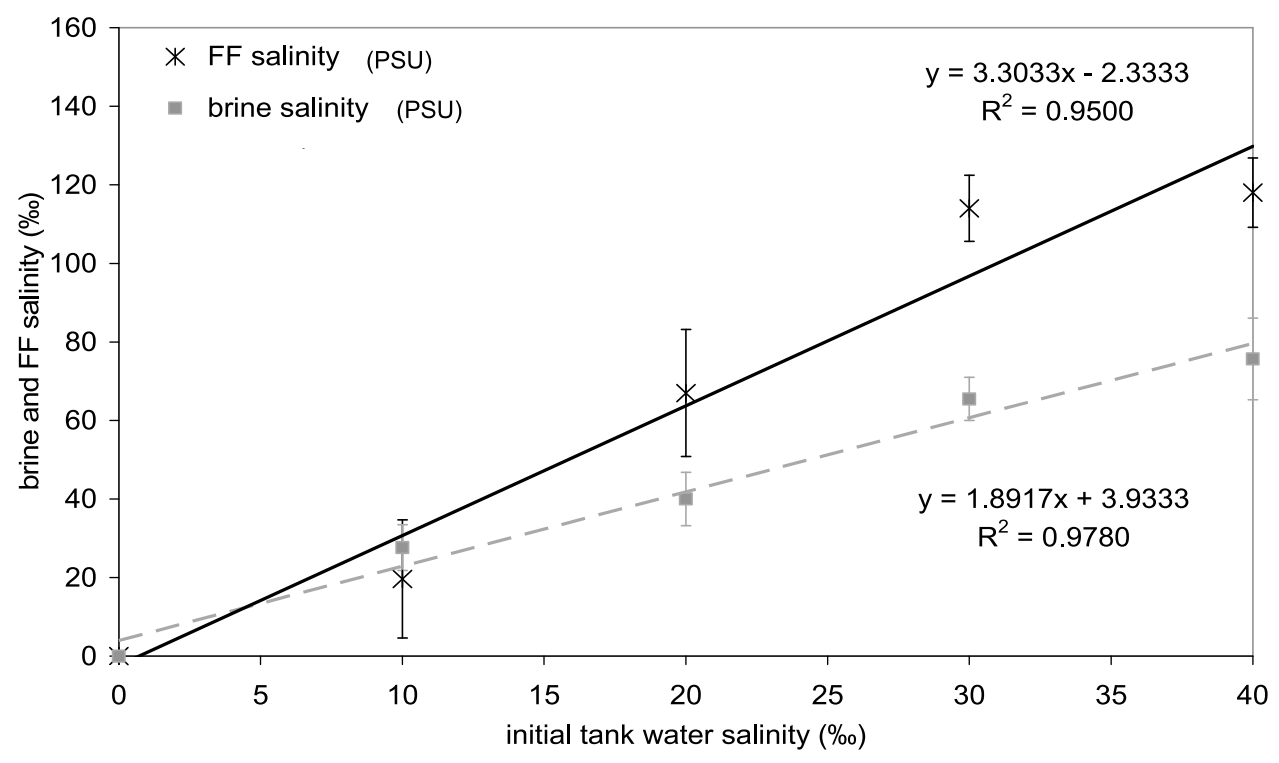

Figure 5. Salinity of artificial frost flowers (black crosses) and brine (gray squares) grown on ice formed by freezing water with initial salinities of 0 to $40 \%$ where error bars show 1 standard deviation of repeat measurements.

[27] The results in Table 2 show that, once again, the colder frost flowers are more saline. However, the dependence on age is sometimes very marked: the older frost flowers were sometimes much more saline, being almost twice the salinity after $48 \mathrm{~h}$ when grown at the warmer temperatures of $-30^{\circ} \mathrm{C}$. However, a run at slightly cooler temperatures did not produce such a marked contrast. More salinity at greater age is consistent with the widely discussed notion that flowers form as fresh water ice from the vapor and wick brine up from the surface as they age. However, the fact that even young frost flowers (not usually sampled in the field) are substantially enriched in brine suggests that wicking occurs continually during their growth (see further discussion in section 5). As might be expected from the dendritic appearance of the growing tips of frost flowers (section 4), the set of samples of tops of frost flowers was less saline despite being grown at colder temperatures. Finally, there is little sign of alteration of the partitioning in ionic composition at colder temperatures.

[28] Specific surface area of some samples was measured, using the Brunauer-Emmett-Teller (BET) method. The surface area apparatus was made at BAS following the recipe of Hanot and Domine [1999] and had previously been used to characterize frost flowers in the field at Hudson Bay by Obbard et al. [2009], who give a full description.

[29] Briefly, the BET technique measures the adsorption of $\mathrm{CH}_{4}$ on the sample at $77 \mathrm{~K}$. The sample is placed in a small stainless steel cylinder at $-25^{\circ} \mathrm{C}$, sealed and cooled to $77 \mathrm{~K}$, and connected to a room temperature stainless-steel manifold complete with valves, turbomolecular pump, and digital manometer. Relative volumes of the sample cylinder and manifold are determined by filling the manifold with $\mathrm{He}$ then expanding the fill into the sample cylinder. When this is repeated with $\mathrm{CH}_{4}$, the resultant pressure is less, due to adsorption on the sample and on the cylinder wall. Further fills of the manifold and expansions into the sample cylinder, without evacuating, create the BET isotherm [see Obbard et al., 2009, and references therein]. A straight-line fit to the isotherm allows the surface area to be determined. This is done first with the empty cylinder, to determine its area, then with the sample to determine the area of sample plus cylinder. From the fit, the net heat of adsorption of $\mathrm{CH}_{4}$ onto the sample can also be found, whose agreement with the net heat of adsorption of ice is a useful measure of the accuracy and quality of the experimental run with the sample. In practice, better results are obtained if the run is completed within an hour: residuals on the fit to the isotherm are then smaller and the work function is closer to that of ice, probably because

Table 2. Composition of Melted Laboratory Frost Flowers ${ }^{\mathrm{a}}$

\begin{tabular}{|c|c|c|c|c|c|c|c|c|}
\hline Sample & $\begin{array}{c}\mathrm{T} \\
\left({ }^{\circ} \mathrm{C}\right)\end{array}$ & $\begin{array}{c}\text { Time } \\
\text { (h) }\end{array}$ & $\mathrm{Na}^{+}$ & $\mathrm{Cl}^{-}$ & $\mathrm{SO}_{4}^{-}$ & $\begin{array}{l}\text { SalC } \\
(\%)\end{array}$ & $\mathrm{SalC} / 35$ & $\mathrm{Cl} / \mathrm{Na}$ \\
\hline A1 & -30 & 6 & 35.4 & 47.2 & 5.7 & 94 & 2.7 & 1.33 \\
\hline $\mathrm{A} 2$ & -30 & 6 & 37.9 & 50.3 & 6.3 & 100 & 2.9 & 1.33 \\
\hline B & slush & 6 & 31.3 & 40.9 & 5.0 & 82 & 2.3 & 1.31 \\
\hline $\mathrm{C} 1$ & -30 & 48 & 68.0 & 97.4 & 2.8 & 183 & 5.2 & 1.43 \\
\hline $\mathrm{C} 2$ & -30 & 48 & 61.5 & 87.8 & 2.8 & 162 & 4.6 & 1.43 \\
\hline D1 & -30 & 72 & 70.0 & 100.7 & 3.0 & 185 & 5.3 & 1.44 \\
\hline D2 & -30 & 72 & 69.0 & 98.6 & 3.3 & 182 & 5.2 & 1.43 \\
\hline E1 & $-30 / 35$ & 6 & 63.7 & 89.0 & 5.0 & 168 & 4.8 & 1.40 \\
\hline E2 & $-30 / 35$ & 6 & 64.7 & 93.2 & 3.1 & 171 & 4.9 & 1.44 \\
\hline F1 & $-30 / 35$ & 12 & 58.7 & 84.1 & 2.6 & 155 & 4.4 & 1.43 \\
\hline $\mathrm{F} 2$ & $-30 / 35$ & 12 & 59.7 & 84.9 & 3.0 & 157 & 4.5 & 1.42 \\
\hline G1 & $-30 / 35$ & 24 & 68.7 & 98.7 & 2.3 & 180 & 5.2 & 1.44 \\
\hline G2 & $-30 / 35$ & 24 & 66.0 & 95.4 & 2.4 & 174 & 5.0 & 1.45 \\
\hline $\mathrm{H}$ & $-25 / 30$ & 6 & 36.7 & 46.7 & 5.9 & 94 & - & 1.27 \\
\hline R1 & -40 & $6^{\mathrm{b}}$ & 39.1 & 54.0 & 3.9 & 103 & 2.9 & 1.38 \\
\hline $\mathrm{R} 2$ & -40 & $6^{\mathrm{b}}$ & 50.0 & 68.0 & 6.1 & 132 & 3.8 & 1.36 \\
\hline R3 & -40 & $6^{b}$ & 34.6 & 46.8 & 4.6 & 92 & 2.6 & 1.35 \\
\hline
\end{tabular}

${ }^{\text {a }}$ All compositions are parts per thousand by mass. Temperature $\left({ }^{\circ} \mathrm{C}\right)$ is that of the air in the cold chamber. Time is the time since starting to cool the seawater with an initial air temperature of $-23^{\circ} \mathrm{C}$, cooling rapidly to that given. SalC is the salinity calculated by adding all ionic components, including $\mathrm{Ca}^{+}, \mathrm{K}^{+}, \mathrm{Mg}^{+}$and $\mathrm{NO}_{3}^{-}$(not listed), and is in units of parts per thousand by mass.

${ }^{\mathrm{b}}$ Tops of frost flowers only. 
Table 3. Measurements of the Specific Surface Area of Frost Flowers Sampled in November $2009^{\mathrm{a}}$

\begin{tabular}{lcccc}
\hline Sample & Weight $(\mathrm{g})$ & Work Function $(\mathrm{J} / \mathrm{mol})$ & $\mathrm{R}^{2}$ & $\mathrm{SSA}\left(\mathrm{cm}^{2} / \mathrm{g}\right)$ \\
\hline FFtops & 5.1 & 2120 & 0.9946 & 87.3 \\
FFbases & 7.0 & 2484 & 0.9962 & 48.4 \\
\hline
\end{tabular}

${ }^{\mathrm{a}}$ The square of the correlation coefficient is for 7 points in the most linear part of the BET isotherm (see text). Note that each sample is the sum from at least 3 frost flowers, so they should be seen as averages of several samples.

taking more time allows temperatures of the room and manifold to vary.

[30] Table 3 shows high correlation coefficients within each analyzed isotherm, and net heats of adsorption close to the recommended value of ice $(2540 \pm 200 \mathrm{~J} / \mathrm{mol}$ [Domine et al., 2007]), demonstrating the accuracy of the BET runs. The specific surface area of the tops of frost flowers was toward the low end of the range obtained with the same apparatus by Obbard et al. [2009] from samples collected in the field at Hudson Bay, which was from 63 to $299 \mathrm{~cm}^{2} / \mathrm{g}$. This is consistent with the briny condition of the surface that was observed in the lab (see discussion below of sea ice surface), as brine might be expected to smooth the irregularities of dendritic structures of the frost flowers and so reduce the surface area. The specific surface area of the bases of frost flowers is consistent with having more smoothing by brine because of being closer to the brine source. Taking measurements of Obbard et al. [2009] of spacing and weight distribution of frost flowers in the field would lead to an expected surface area amplification of 1.8 for frost flowers with the mean specific surface area (SSA) of these tops and bases $\left(68 \mathrm{~cm}^{2} / \mathrm{g}\right)$. This confirms the results of Obbard et al. [2009] and Domine et al. [2005] that the surface area of frost flowers is generally only slightly larger than that of the underlying sea ice. Since the leaf of a flower inevitably has an area of twice the underlying area it covers, this suggests that it is unusual to have multiple leaves covering each other, and that the surface structure essentially presents itself as two dimensional, gaining little extra area from any fractal nature or from the third dimension, unlike a snowpack.

[31] Time-lapse photography showed examples of flowers forming and growing, with an obviously different texture between flower tops and bases, consistent with the lesser SSA of the bases. An example is shown in Figure 6, where the bases are clearly more compacted, consistent with the wicking of brine from the surface (see section 5). Alternatively, it could be due to metamorphism: dendritic materials metamorphose with time, whereby vapor and surface diffusion move material from areas with small radii of curvature to areas of larger radii of curvature; all dendritic materials exhibit metamorphism, including those produced by the solidification of alloys [Marsh and Glicksman, 1996]. Or, it could be due to a combination of the two phenomena. Figure 6 also shows the dendritic tops of the flowers, which we speculate are still growing.

[32] Note that the photographs in Figures 6 to 9 were taken with a wide-angle lens at a distance of up to $0.8 \mathrm{~m}$, in indoor lighting, and during the growing process so flowers are widely spaced. Figures 8 and 9 are also considerably blown up so have much lower apparent resolution. The photographs of flowers in the field in Figures 4 and 5 of Obbard et al. [2009] were taken with a macro lens at a distance of $2 \mathrm{~cm}$, in sunlight so strong it had to be partly shielded so that the images could be viewed on the camera's laptop (the camera itself had no screen), and were taken after growth was complete so flowers were very dense. Taking the differences in camera, lighting, growth stage and degree of blow-up into account, the laboratory and field flowers show great similarity of dendritic structure and are about the same size.

[33] The time-lapse photography also showed examples of flowers forming with wide spacing, growing, then shrinking dramatically. We speculate that this is because flowers are sometimes growing downward and reaching the surface, then wicking brine and partially remelting. Flowers do not grow exclusively upward: Movies S1 and S2 in the auxiliary material show very clear sideways growth, and sideways growth has been previously observed by Style and Worster [2009]. ${ }^{1} \mathrm{We}$ speculate that downward growth is possible because the supply of vapor can be from the ice and brine below, and although we do not have 3-D movies, our 2-D movies (Movies S1 and S2) have every appearance of downward growth from time to time. It is also possible that a pustule in the nearby surface (see section 4) broke and flooded the vicinity with fresh brine. Examples are shown in Figures 8 and 9 .

[34] Figures 6 to 9 and Movies S1 and S2 (in the auxiliary material) show clear examples of fresh growth of the tips of frost flowers as dendrites, which we speculate to be comparatively free of wicking; hence, the observed lower salinity of frost flower tops in Table 2.

\section{The Sea Ice Surface}

[35] The time-lapse photography in our tank system allowed us to observe the mobility of freshly forming sea ice, as shown in part of Figure 9 and in Figure 10, after the stage at which the mush appears to have solidified. At this point some

${ }^{1}$ Auxiliary materials are available in the HTML. doi:10.1029/ 2010JD015144.

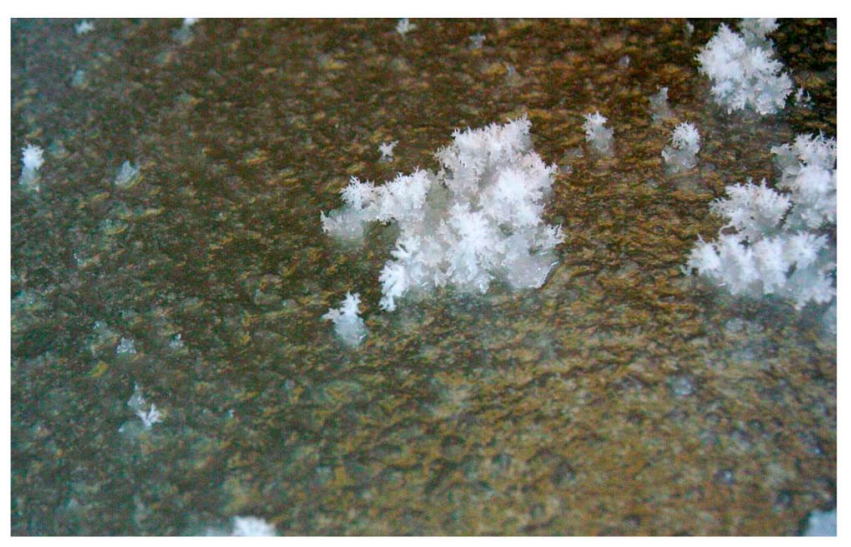

Figure 6. Photograph of frost flowers growing on the surface of sea ice in the tank, with the chamber air at $-50^{\circ} \mathrm{C}$, on 30 September 2009. This picture was taken $24 \mathrm{~h}$ after the start of the run. The ice surface formed after $9 \mathrm{~h}$, and flowers first formed after $10.3 \mathrm{~h}$. The picture shows a scene of about 20 by $12 \mathrm{~cm}$ and is from file 1459 of the sequence. Significant contrast enhancement has been used on this image. 

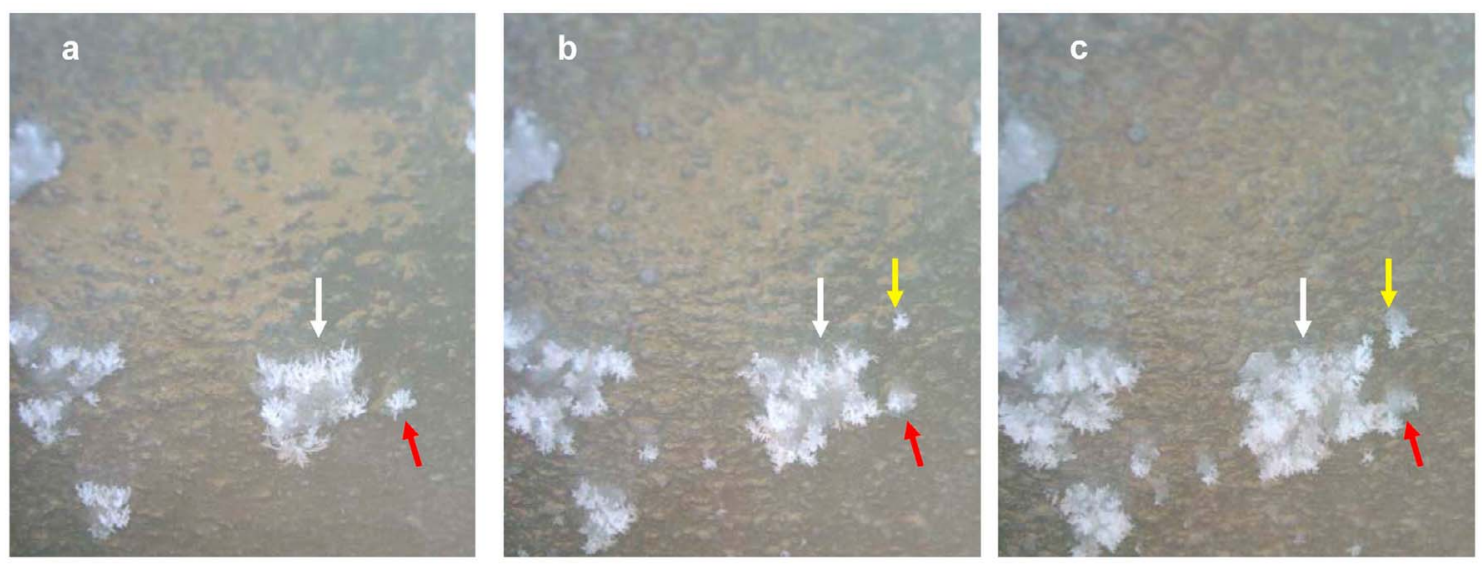

Figure 7. Time-lapse photographs of frost flowers growing on the surface of sea ice in the tank, with the chamber air at $-50^{\circ} \mathrm{C}$, on 30 September 2009 . Looking at the large lower frost flower at the white arrow, the base of the flower is less dendritic than its top, consistent with a smaller specific surface area at the base as in Table 3. The process is more pronounced following the smaller flowers at red and yellow arrows. As the flowers grow with time, so does the amount that is less dendritic. These pictures are at intervals of 90 and $150 \mathrm{~min}$, respectively, (a) the first being $20 \mathrm{~h}$ after the start of the run. The ice surface formed after $9 \mathrm{~h}$, and flowers first formed after $10.3 \mathrm{~h}$. Each picture shows a scene of about 10 by $14 \mathrm{~cm}$. Figure $7 \mathrm{a}$ is from file 1219 of the sequence.

flowers have started to grow, but at very wide spacing. This mobility of the surface was very obvious and sometimes extreme when watching the photographs as a video (see online supplement). It is rather harder to discern from the adjacent stills shown here. The mobility takes the form of pustules that erupt upwards. The timescale for growth and eruption of a pustule is from less than $1 \mathrm{~min}$ to between 2 and 3 min (see online supplements). The eruptions result in new brine being expelled to the surface, which therefore remained rather wet - if a cooling run was interrupted at this stage, the wet surface was very obvious on visual inspection, with a brine thickness of up to $1 \mathrm{~mm}$. During one such interrupted run, a small hole was made in the wet ice with a batteryoperated drill, and the top few millimeters of ice were hard, but then the drill broke through the lower layers very easily.

[36] This wetness reinforces our conclusion from the photographs of frost flower growth above that wicking occurs continually during this growth. The pustules also lead to a surface that is far from flat and to the ice being cloudy, as observed of sea ice in the field when formed at low air temperatures, and unlike fresh water ice on lakes. We speculate that this lack of flatness allows protrusions that rise above the brine and so provide locations on which flowers can start to form.
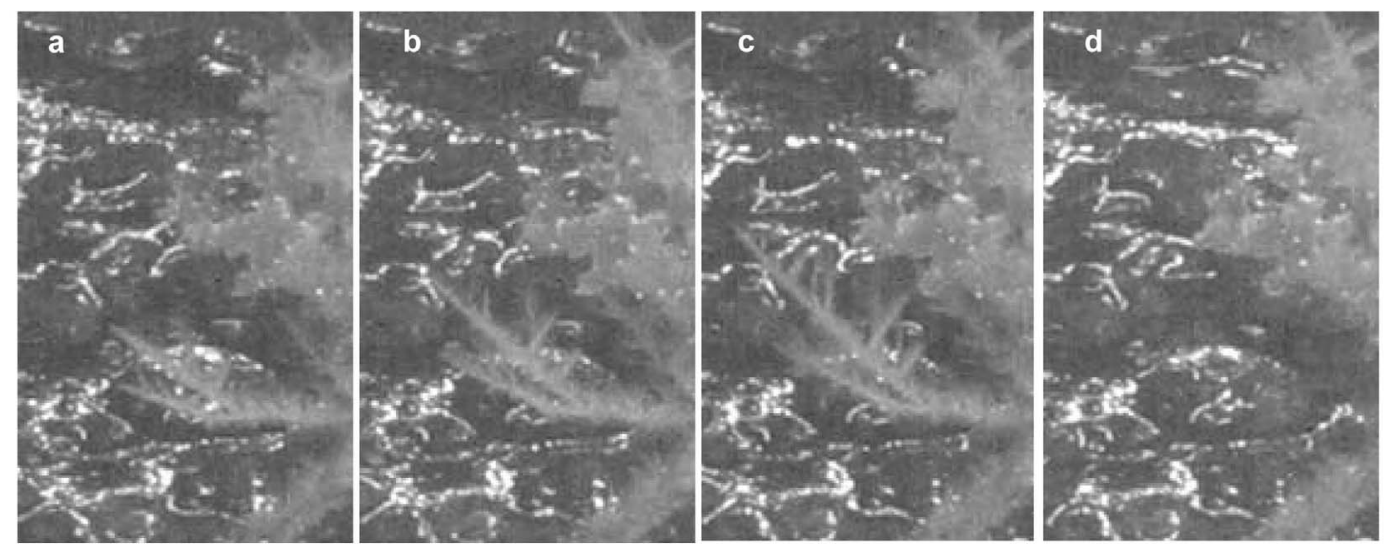

Figure 8. Time-lapse photographs of a part of a frost flower growing in the laboratory, and shrinking as it contacts the brine-laden surface. Photographs are at intervals of 10, 22 and 3 min respectively, so that the part of the flower growing in the center of Figures $8 \mathrm{a}$ to $8 \mathrm{c}$ disappears rapidly between Figures $8 \mathrm{c}$ and $8 \mathrm{~d}$. Each photograph shows a scene of about 0.9 by $1.5 \mathrm{~cm}$. The sequence started $19 \mathrm{~h}$ after freezing commenced, with an air temperature of $-50^{\circ} \mathrm{C}$, on 20 July 2009. The ice surface formed after $8.5 \mathrm{~h}$. Figure $8 \mathrm{a}$ is from file 1164 of the sequence. 

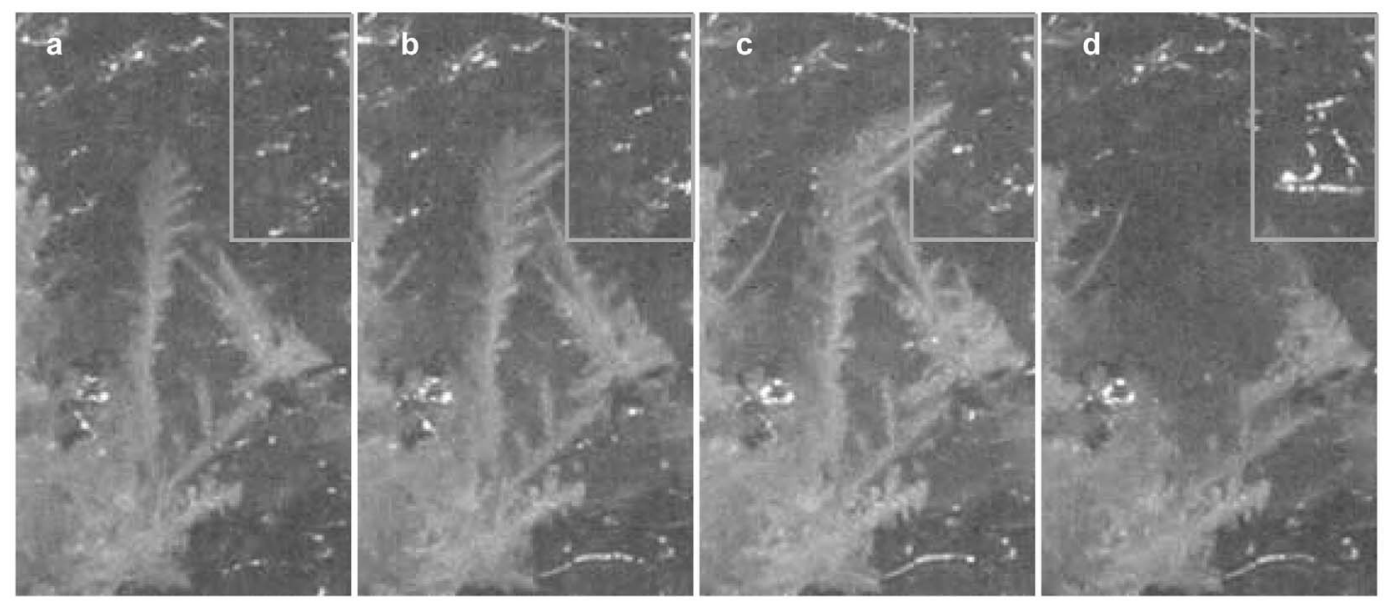

Figure 9. Same as Figure 8 but at intervals of $10 \mathrm{~min}, 25 \mathrm{~min}$, and $1 \mathrm{~min}$, respectively, so that the parts of the flower that disappear between Figures $8 \mathrm{c}$ and $8 \mathrm{~d}$ do so even more rapidly; and each photograph shows a scene of about 0.9 by $1.7 \mathrm{~cm}$. The sea ice surface within the gray box exhibits the kind of mobility shown more widely in Figure 10.

[37] Such mobility of the surface after the mushy ice at least partly solidified was observed on the many experimental runs for which we have time-lapse photographs, so we conclude it is a general feature of wind-free sea ice during freezing at low temperatures. Although these observations are consistent with sea ice being a mushy layer in the technical sense of the term (rigid matrix of pure solid bathed in its impurity rich melt, as used in materials science [e.g., Feltham et al., 2006]), they are not consistent with some earlier laboratory observations of thick sea ice being surrounded or covered by brine pools during freezing. As stated above, we believe that such observations were the result of flooding of the surface via cracks, due to the build up of pressure beneath the ice surface as further freezing and expansion progressed.

[38] In the field, several observers have commented on the brine skim up to $2 \mathrm{~mm}$ thick that develops on the surface during the early stages of sea ice growth [Perovich and
Richter-Menge, 1994, and references therein]. The brine skim was ubiquitous in the field, and lasted well into the stage of frost flower growth. However, none of these observers have described the pustules and surface mobility that we observed. Possibly they are not easy to see without timelapse photography displayed as a movie, or possibly an important aspect of our laboratory conditions was not representative of the field (e.g., depth of water below the ice, or its turbulence).

\section{Aerosols From Frost Flowers}

[39] The seawater tank and cold chamber included a sampling line for measurements of aerosol by external instruments. The line was cooled below $-10^{\circ} \mathrm{C}$, aspirated, and sampled isokinetically from the head space above the sea ice. Residence time of samples in the line was between 2 and
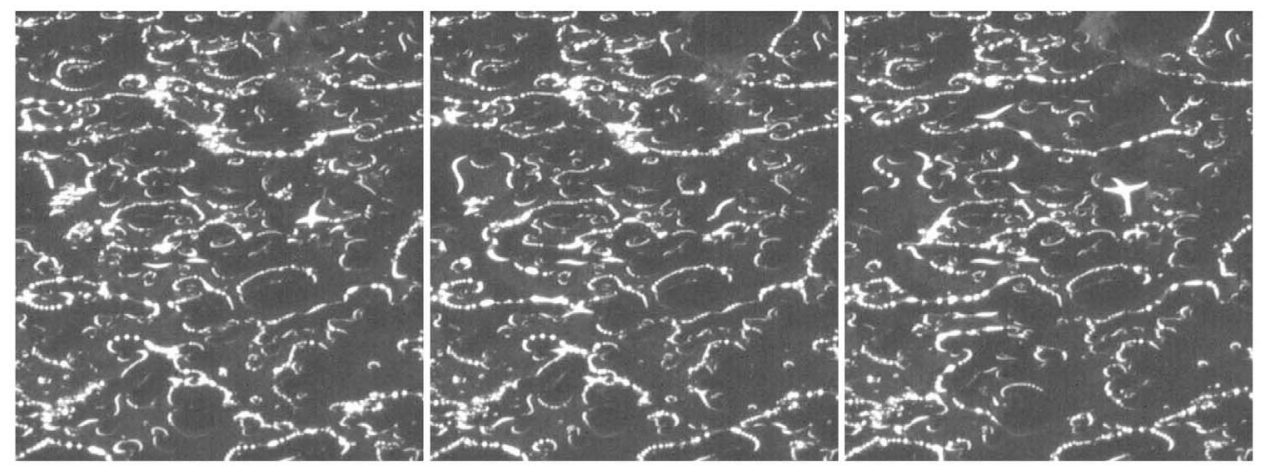

Figure 10. Time-lapse photographs of the surface of the sea ice during its freezing in the laboratory. This sequence is taken after the formation of a continuous ice layer across the surface of the seawater tank but before substantial growth of frost flowers. Pustules several millimeters across are seen forming at the surface, then sometimes dissipating. Photographs are at $14 \mathrm{~min}$ intervals, and each shows a scene of about 3 by $4 \mathrm{~cm}$. The sequence started $13.9 \mathrm{~h}$ after freezing commenced, with an air temperature of $-40^{\circ} \mathrm{C}$, on $6 \mathrm{July}$ 2009. The ice surface first formed after $10 \mathrm{~h}$. Figure 10 (left) is from file 1832 of the sequence. 
Table 4. Measurements of Smoke by the Grimm Dust Monitor, Inside the Cold Chamber at Room Temperature and Then Outside Sampling the External Aerosol Line ${ }^{\mathrm{a}}$

\begin{tabular}{lllll}
\hline & \multicolumn{4}{c}{ Grimm Channel } \\
\cline { 2 - 5 } & \multicolumn{1}{c}{2} & 7 & \multicolumn{1}{c}{10} & \multicolumn{1}{c}{14} \\
\hline Diameter $(\mu \mathrm{m})$ & 0.45 & 1.8 & 4.5 & 18 \\
Grimm inside & $1.0 \times 10^{4}$ & 2.6 & $7.9 \times 10^{-3}$ & $9.9 \times 10^{-6}$ \\
Grimm outside & $0.9 \times 10^{4}$ & 1.6 & $4.5 \times 10^{-3}$ & $2.5 \times 10^{-6}$ \\
\hline
\end{tabular}

${ }^{\mathrm{a}}$ The FSSP pump was on, thereby activating the external line. The measurements are of number concentration per unit radius, $\mathrm{dN} / \mathrm{dR}$ $\left(\mu \mathrm{m}^{-1} \mathrm{~cm}^{-3}\right)$, at selected size bins. Minimum detectable amounts were less than $1 \times 10^{-6}$ at $18 \mu \mathrm{m}$ diameter.

$4 \mathrm{~s}$. The cooling was not applied to the last $0.5 \mathrm{~s}$, nor to the instruments themselves.

[40] Three optical particle counters were routinely deployed: (1) PMS ASASP-X, measuring particle diameters from 0.1 to $3 \mu \mathrm{m}$, in 31 size bins, (2) PMS FSSP-100, measuring particle diameters from 0.5 to $47 \mu \mathrm{m}$, and (3) Grimm Dust monitor 1.108 , measuring particle diameters from 0.3 to $20 \mu \mathrm{m}$, in 15 size bins.

[41] Note that the size bins in these counters had no gaps between them: all particles within the quoted size ranges were detected, although particles smaller than the minimum $(0.1 \mu \mathrm{m}$ for the ASASP-X) were not detected. The ASASP-X measured the aerosol after it had been partially dried, whereas the FSSP and Grimm measured the aerosol with no modification other than warming after the cooled section of the external sample line (see fifth paragraph of this section).

[42] The transmission of the external sample line was measured by tests with smoke inside the tank system, with the Grimm dust monitor deployed alternately inside and outside the cold room. At low ambient temperatures, smoke is inclined to be lost on surfaces, so tests were conducted at room temperature. The background ambient air in the tank before smoke production contained less than $1 / 100$ of the particle density of the air with smoke. Table 4 shows that the transmission loss in the external line was negligible at sizes less than $0.3 \mu \mathrm{m}$, about $40 \%$ at $1 \mu \mathrm{m}$, and about $75 \%$ at $10 \mu \mathrm{m}$. At these larger sizes any aerosol significantly above background amounts would be clearly observed via the external sample line.

[43] The potential for uptake from the surface inside the tank system was also measured, by tests with talcum powder spread on a plate at the height of the ice surface in the otherwise empty water tank. Talcum powder has a typical mean diameter of $10 \mu \mathrm{m}$, though some particles can be as large as $50 \mu \mathrm{m}$. Again, the aerosol in the external sample line was measured by the Grimm dust monitor. The results in Figure 11 show that at $3.3 \mathrm{~m} / \mathrm{s}$, aerosol could indeed be uplifted from the location of the ice surface, and could be observed externally.

[44] In order to investigate aerosol from frost flowers, mature frost flowers were exposed to a wind stress from the particle-free air inside the tank system. The wind speed at the height of the frost flowers ranged up to $12 \mathrm{~m} / \mathrm{s}$ using the bellows system (see above), both semicontinuous and in focused gusts. Contrary to our expectation, no aerosol in the diameter range from 0.1 to $47 \mu \mathrm{m}$ was observed during frost flower growth. These measurements were repeated several times to confirm this surprising conclusion. In some cases gusts destroyed the frost flowers, but still no aerosol was observed - we presume the detached pieces were large and coherent enough to fall to the briny surface and be captured. Note that the short section of external sample line that was not cooled, together with the warm FSSP and Grimm sample chambers, allowed up to $2 \mathrm{~s}$ for dehydration and so shrinking of larger frost flower fragments. However, fragments soaked in brine would shrink marginally, as seawater aerosol only shrinks to about half its size at a relative humidity of $80 \%$. Furthermore, in the field, any partially dried aerosol larger than $47 \mu \mathrm{m}$ would not be lofted for very long or transported very far.

[45] To make a final confirmation that frost flower aerosol was not being lost in the external sampling line, the Grimm dust monitor and ASASPX were again deployed inside the cold room, as in the smoke tests described above. Their inlets were positioned within $10 \mathrm{~mm}$ of the frost flowers field, and aerosol was monitored for up to $10 \mathrm{~min}$ - longer sampling times were not possible as the instruments would get too cold. This was again for a range of wind speeds up to $12 \mathrm{~m} / \mathrm{s}$. The background count was close to zero and no statistically significant concentration was measured by either instrument.

[46] In conclusion, no aerosol in the diameter range 0.1 to $47 \mu \mathrm{m}$ was produced by the wind stress on the frost flowers. This surprising conclusion is consistent with the stability of frost flower samples when being collected for ionic and surface area analysis: collection of pieces from the bottoms of flowers could be scraped off the ice surface with a spatula, but took some effort in scraping. On some occasions it took

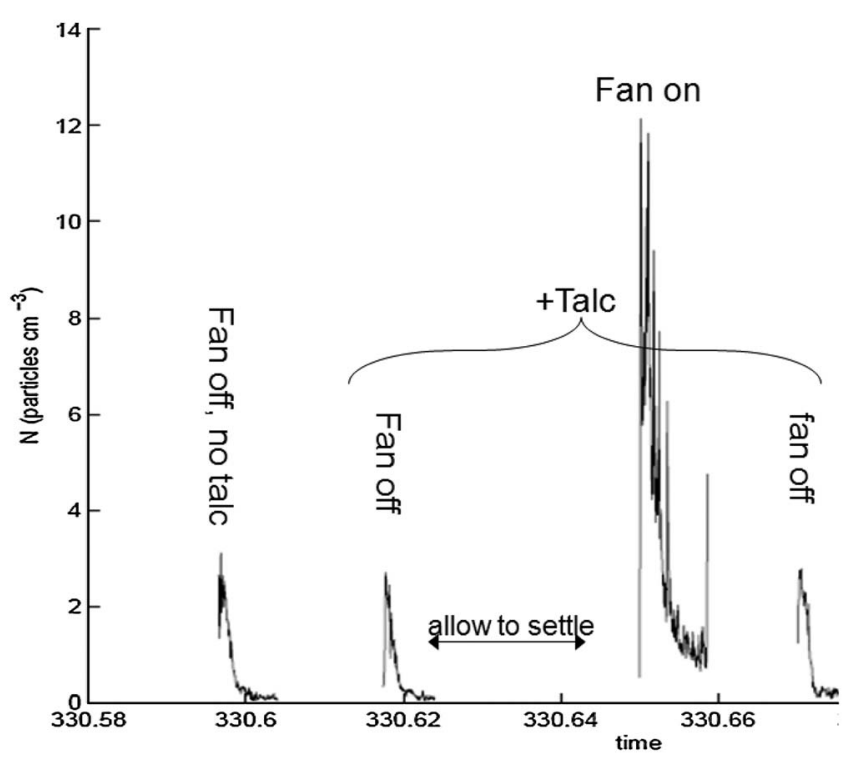

Figure 11. Particle density in Grimm channel $10(4.5 \mu \mathrm{m}$ diameter, $1 \mu \mathrm{m}$ wide) while testing uplift of talcum powder from the water tank. If the initial aerosol filters were left in place upwind of the water tank, flow was too slow at $<2 \mathrm{~m} / \mathrm{s}$ to cause uplift. After removing the filters, there was always a surge of ambient aerosol for a few minutes after activating the aerosol sample line, but there was a sixfold increase if talcum powder was present and the wind was $3.3 \mathrm{~m} / \mathrm{s}$ or more. The time axis is in days and spans about $2.5 \mathrm{~h}$. 
an impact on the side of the seawater tank to dislodge frost flower fragments.

[47] We did not observe any dehydration of frost flowers after their formation, probably because the tank system was unable to create the low humidity conditions required. If significant dehydration were to occur, some parts of the frost flowers could presumably become more fragile and so susceptible to destruction by wind and so creation of aerosol, but we were unable to test this possibility.

\section{Conclusions}

[48] In the laboratory, we have measured how frost flower salinities and composition depend on temperature of the air above the seawater and ice, and on the salinity of the seawater. We have also measured their surface area, which is small and so is consistent with recent field measurements from the Arctic. Unlike some previous laboratory measurements of frost flower growth, we avoided overpressurizing the liquid water beneath the ice during the freezing process. This avoided fresh cracks in the ice surface and resultant flooding with seawater, eliminating an otherwise complicating factor in the laboratory measurements.

[49] The measurements and observations show the following.

[50] 1. Salinity of frost flowers increased at colder air temperatures and with longer growth times, reaching over 5 times that of the original seawater at $-32^{\circ} \mathrm{C}$ and $24 \mathrm{~h}$. This increase with age had been widely speculated but not previously observed.

[51] 2. Surface area amplification was modest (about 2), consistent with previous Arctic measurements at a variety of temperatures and salinities.

[52] 3. No aerosol could be observed from frost flowers, despite winds in gusts up to $12 \mathrm{~m} / \mathrm{s}$. This is consistent with the rather stable nature of the flowers when attempting to handle and sample them. Hence we are now convinced that frost flowers are unlikely to be the major direct source of sea salt aerosol in the Antarctic, and given their low surface area they are also unlikely to be the main source of direct halogen production in the sea ice zone. This leaves wind-blown partly saline snow [Yang et al., 2008] as the more probable source. However, while our experiments were clear about the lack of aerosol production, they have not tested the possibility of aerosol production if low humidity is able to cause extensive drying of frost flowers.

[53] 4. During the freezing process, the sea ice surface is highly mobile even after an apparently continuous film of ice has formed. The surface appears to have pustules which then burst, giving it the characteristic appearance of sea ice (cloudy) as opposed to lake ice (clear), and the surface has a brine skim of thickness up to $1 \mathrm{~mm}$.

[54] 5. Frost flowers appear to wick from this brine skim at various points during their growth, often greatly reducing their apparent size before they continue to grow afresh. The ionic composition and salinity of younger frost flowers strongly suggests that wicking occurs continually during their growth.

[55] 6. The bases of frost flowers have smaller specific surface area and appear less dendritic than the tops. This could be due to the wicking of brine, or to the metamorphism with time observed in all dendritic materials, or to a combination of the two.

[56] Acknowledgments. The authors would like to thank Florent Dominé and Jean-Charles Gallet of the Laboratoire de Glaciologie et Géophysique de l'Environnement (LGGE) in France and Michael Kerbrat of the Paul Scherrer Institute in Switzerland for advice and training on the BET apparatus. We are indebted to Rob Style and Grae Worster of DAMTP in Cambridge for helpful conversations and previews of their frost flower results and to Louise Althorpe at BAS for assistance with measurements of ionic composition. The participation of Howard Roscoe and Eric Wolff was funded by the British Antarctic Survey's Polar Science for Planet Earth program, which is funded by the UK's Natural Environment Research Council (NERC). The participation of Rachel Obbard, Sarah Walker, and Barbara Brooks was funded by NERC grant NE/D004276/1.

\section{References}

Alvarez-Aviles, L., W. R. Simpson, T. A. Douglas, M. Sturm, D. Perovich, and F. Domine (2008), Frost flower chemical composition during growth and its implications for aerosol production and bromine activation, J. Geophys. Res., 113, D21304, doi:10.1029/2008JD010277.

Bottenheim, J. W., J. D. Fuentes, D. W. Tarasick, and K. G. Anlauf (2002), Ozone in the Arctic lower troposphere during winter and spring 2000 (ALERT2000), Atmos. Environ., 36, 2535-2544, doi:10.1016/S13522310(02)00121-8.

Dauphinee, T. M., et al. (1980), The electrical conductivity of weight diluted and concentrated standard sea water as a function of salinity and temperature, IEEE J. Oceanic Eng., 5, 28-41, doi:10.1109/JOE.1980. 1145439 .

Domine, F., A. S. Tailandier, W. R. Simpson, and K. Severein (2005), Specific surface area, density and microstructure of frost flowers, Geophys. Res. Lett., 32, L13502, doi:10.1029/2005GL023245.

Domine, F., A.-S. Tailandier, and W. R. Simpson (2007), A parameterization of the specific surface area of seasonal snow for field use and for models of snowpack evolution, J. Geophys. Res., 112, F02031, doi:10.1029/2006JF000512.

Feltham, D. L., N. Untersteiner, J. S. Wettlaufer, and M. G. Worster (2006), Sea ice is a mushy layer, Geophys. Res. Lett., 33, L14501, doi:10.1029/ 2006GL026290.

Friess, U., J. Hollwedel, G. Konig-Langlo, T. Wagner, and U. Platt (2004), Dynamics and chemistry of tropospheric bromine explosion events in the Antarctic coastal region, J. Geophys. Res., 109, D06305, doi:10.1029/ 2003JD004133.

Hall, J. S., and E. W. Wolff (1998), Causes of seasonal and daily variations in aerosol sea-salt concentrations at a coastal Antarctic station, Atmos. Environ., 32, 3669-3677, doi:10.1016/S1352-2310(98)00090-9.

Hanot, L., and F. Domine (1999), Evolution of the surface area of a snow layer, Environ. Sci. Technol, 33, 4250-4255, doi:10.1021/es9811288.

Kaleschke, L., et al. (2004), Frost flowers on sea ice as a source of sea salt and their influence on tropospheric halogen chemistry, Geophys. Res. Lett., 31, L16114, doi:10.1029/2004GL020655.

Marsh, S. P., and M. E. Glicksman (1996), Overview of geometric effects on coarsening of mushy zones, Metall. Mater. Trans. A, 27, 557-567, doi:10.1007/BF02648946.

Martin, S., Y. Yu, and R. Drucker (1996), The temperature dependence of frost flower growth on laboratory sea ice and the effect of the flowers on infrared observations of the surface, J. Geophys. Res., 101, 12,111-12,125, doi:10.1029/96JC00208.

Massom, R. A., et al. (2001), Snow on Antarctic sea ice, Rev. Geophys., 39, 413-445, doi:10.1029/2000RG000085.

Obbard, R. W., H. K. Roscoe, E. W. Wolff, and H. M. Atkinson (2009), Frost flower surface area and chemistry as a function of salinity and temperature, J. Geophys. Res., 114, D20305, doi:10.1029/2009JD012481.

Perovich, D. K., and J. A. Richter-Menge (1994), Surface characteristics of lead ice, J. Geophys. Res., 99, 16,341-16,350, doi:10.1029/94JC01194.

Platt, U., and E. Lehrer (Eds.) (1997), Arctic Tropospheric Ozone Chemistry (ARCTOC), Air Pollut. Res. Rep. 64, pp. A89-A98, Eur. Comm., Brussels.

Rankin, A. M., V. Auld, and E. W. Wolff (2000), Frost flowers as a source of fractionated sea salt aerosol in the polar regions, Geophys. Res. Lett., 27, 3469-3472, doi:10.1029/2000GL011771.

Rankin, A. M., E. W. Wolff, and S. Martin (2002), Frost flowers: Implications for tropospheric chemistry and ice core interpretation, J. Geophys. Res., 107(D23), 4683, doi:10.1029/2002JD002492.

Simpson, W. R., D. Carlson, G. Honninger, T. A. Douglas, M. Sturm, D. Perovich, and U. Platt (2007), First-year sea-ice contact predicts bromine monoxide $(\mathrm{BrO})$ levels at Barrow, Alaska better than potential frost 
flower contact, Atmos. Chem. Phys., 7, 621-627, doi:10.5194/acp-7621-2007.

Style, R. W., and M. G. Worster (2009), Frost flower formation on sea ice and lake ice, Geophys. Res. Lett., 36, L11501, doi:10.1029/2009GL037304.

Ulander, L. M. H., A. Carlstrom, and J. Askne (1995), Effect of frost flowers, rough saline snow and slush on the ERS-1 backscatter of thin Arctic sea-ice, Int. J. Remote Sens., 16, 3278-3305.

Wagenbach, D., F. Ducroz, R. Mulvaney, L. Keck, A. Minikin, M. Legrand, J. S. Hall, and E. W. Wolff (1998), Sea-salt aerosol in coastal Antarctic regions, J. Geophys. Res., 103, 10,961-10,974, doi:10.1029/97JD01804.
Yang, X., J. A. Pyle, and R. A. Cox (2008), Sea salt aerosol production and bromine release: Role of snow on sea ice, Geophys. Res. Lett., 35 , L16815, doi:10.1029/2008GL034536.

B. Brooks, A. V. Jackson, M. H. Smith, and S. J. Walker, School of Earth and Environment, University of Leeds, UK.

R. W. Obbard, Thayer School of Engineering, Dartmouth College, New Hampshire, USA.

H. K. Roscoe and E. W. Wolff, British Antarctic Survey, Madingley Road, Cambridge CB3 0ET, UK. (hkro@bas.ac.uk) 